\title{
Cross-linking of the Dermo-Epidermal Junction of Skin Regenerating from Keratinocyte Autografts \\ Anchoring Fibrils Are a Target for Tissue Transglutaminase
}

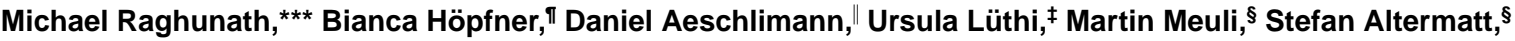 \\ Rita Gobet, ${ }^{\S}$ Leena Bruckner-Tuderman, $"$ and Beat Steinmann* \\ *Division of Metabolic and Molecular Diseases, ${ }^{\ddagger}$ Central Laboratory for Electron Microscopy, ${ }^{\S}$ Pediatric Burn Center of the Children’s \\ Hospital, University of Zürich, Zürich, Switzerland; "Department of Medicine, University of Wisconsin, Madison, Wisconsin 53706; and \\ ${ }^{\pi}$ Department of Dermatology and ${ }^{* *}$ Institute of Physiological Chemistry and Pathobiochemistry, University of Münster, Münster, \\ Germany
}

\begin{abstract}
Since transglutaminases create covalent $\gamma$-glutamyl- $\epsilon$-lysine cross-links between extracellular matrix proteins they are prime candidates for stabilizing tissue during wound healing. Therefore, we studied the temporo-spatial expression of transglutaminase activity in skin regenerating from cultured epithelial autografts in severely burned children by the specific incorporation of monodansylcadaverine into cryostat sections from skin biopsies obtained between $5 \mathrm{~d}$ to 17 mo after grafting. The dansyl label was subsequently immunolocalized in the epidermis, dermal connective tissue, and along the basement membrane. Incubation of cryosections of normal and regenerating skin with purified tissue transglutaminase confirmed the dermo-epidermal junction and the papillary dermis as targets for this enzyme and revealed that in regenerating skin transamidation of the basement membrane zone was completed only 4-5 mo after grafting. Immunoelectron microscopy revealed that three distinct regions on the central portion of anchoring fibrils were positive for monodansylcadaverine in normal skin which were negative during the initial phase of de novo formation of anchoring fibrils in regenerating skin. Biochemically, we identified collagen VII as potential substrate for tissue transglutaminase. Thus, tissue transglutaminase appears to play an important role not only in cross-linking of the papillary dermis but also of the dermo-epidermal junction in particular. (J. Clin. Invest. 1996. 98:1174-1184.) Key words: wound healing $\bullet$ transglutaminase $\cdot$ burns $\bullet$ skin • collagen VII
\end{abstract}

\section{Introduction}

It is a common observation that cultured keratinocyte autografts (cultured epithelial autografts [CEA], ${ }^{1}$ see reference 1) are fragile and sensitive to mechanical shearing forces for at least $2 \mathrm{mo}$ post grafting (pg) (Gobet, R., S. Altermatt, C. Meuli-Simmen, M.

Address correspondence to Michael Raghunath, M.D., Institute of Physiological Chemistry and Pathobiochemistry, University of Münster, Waldeyerstr. 15, D-48149 Münster, Germany. Phone: 251-835590; FAX: 251-83-5596; E-mail: raghuna@uni-muenster.de

Received for publication 20 March 1996 and accepted in revised form 26 June 1996.

J. Clin. Invest.

(C) The American Society for Clinical Investigation, Inc. 0021-9738/96/09/1174/11 \$2.00

Volume 98, Number 5, September 1996, 1174-1184
Raghunath, M. Benathan, A. Dietl, and M. Meuli, manuscript submitted for publication). During this critical period, separation of the newly formed epidermis from the neodermis can occur either spontaneously or by mechanical friction. This points to a transitory instability of the dermo-epidermal junction (DEJ) either by absence of supramolecular structures or their cross-linking, or both. The integrity of the DEJ is largely guaranteed by anchoring fibrils, which is illustrated by the fact that mutations and functional deficits of their major component, collagen VII (2), cause a blistering skin disease collectively known as dystrophic epidermolysis bullosa (for review see reference 3 ). Transglutaminase-derived cross-links were demonstrated recently by immunohistochemistry along the basement membrane (4). In fact, several basement membrane constituents (BM-40/osteonectin/ SPARC and nidogen/entactin) are good substrates for tissue transglutaminase (4-7). These findings suggest that transglutaminase cross-linking contributes to the stability of the DEJ and, consequently, may play a role in wound healing processes in skin and in particular in the integration of CEA. Since CEA are increasingly used to cover burn wounds (8) and other large skin defects, understanding the mechanisms underlying tissue integration is therefore of great clinical importance.

Transglutaminases form a family of proteins with at least six different gene products in higher vertebrates that have specialized in the cross-linking of protein assemblies in different physiological situations (9). Transglutaminases (E.C. 2.3.2.13) catalyze a $\mathrm{Ca}^{2+}$-dependent transfer reaction between the $\gamma$-carboxamide group of a peptide-bound glutamine residue and various primary amines (9-11). Most commonly, $\gamma$-glutamyl- $\epsilon$-lysine cross-links are formed in or between proteins by reaction with the $\epsilon$-amino group of lysine residues. The role of keratinocyte and epidermal transglutaminase in crosslinking proteins forming the cornified cell envelope in terminal differentiation of keratinocytes is well established (12-14). In fact, a congenital keratinization disorder, autosomal recessive lamellar ichthyosis, has been linked recently to mutations in the gene coding for keratinocyte transglutaminase $(15,16)$. Less understood is the function of tissue transglutaminase which is expressed widely in vertebrate tissues $(5,17,18)$ and is also synthesized by dermal fibroblasts ${ }^{2}(19)$ and basal kera-

1. Abbreviations used in this paper: CEA, cultured epithelial autografts; DEJ, dermo-epidermal junction; FXIII, coagulation Factor XIII; MDC, monodansylcadaverine; pg, post grafting; RT, room temperature.

2. Raghunath, M., Th. Bächi, D. Aeschlimann, and B. Steinmann, manuscript submitted for publication. 
MDC
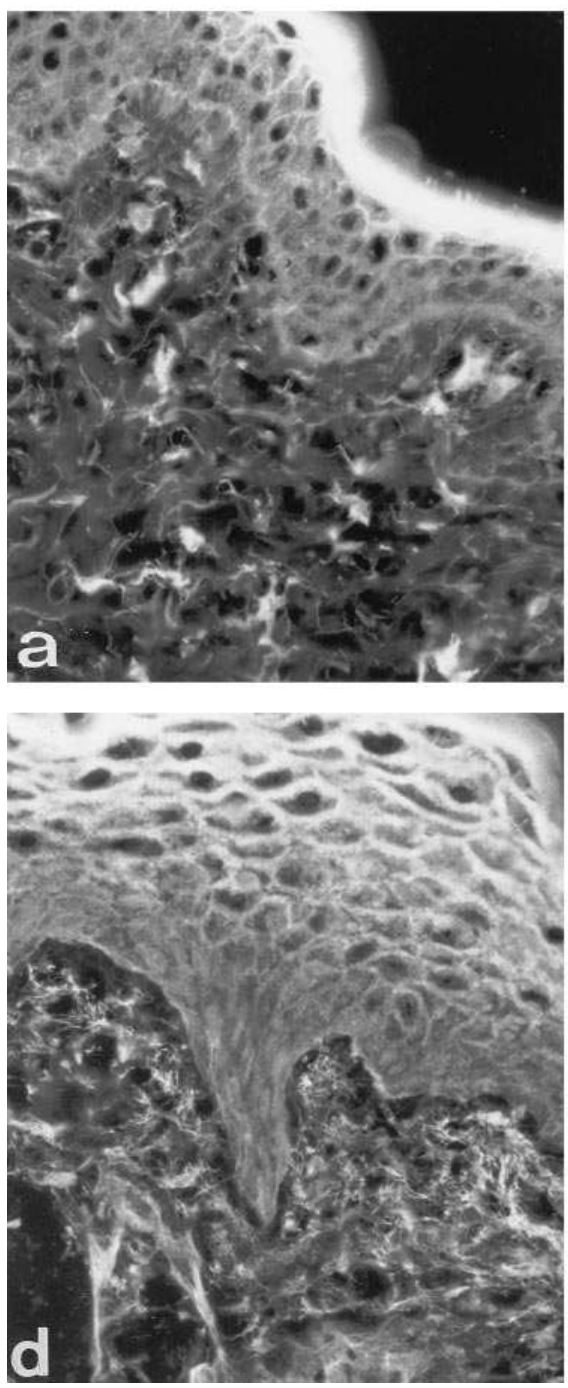

$\mathrm{MDC}+\mathrm{Pu}$
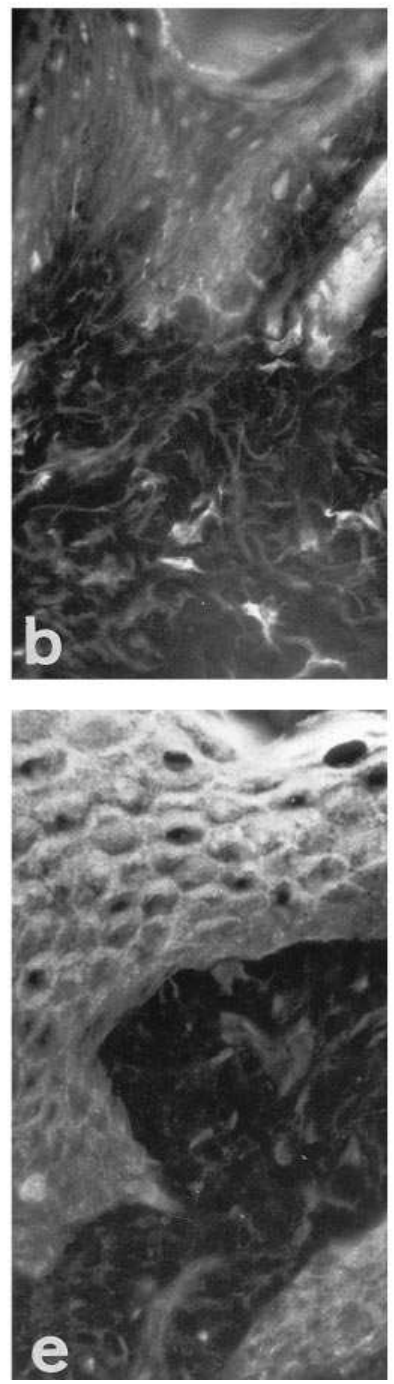

MDC + TGII

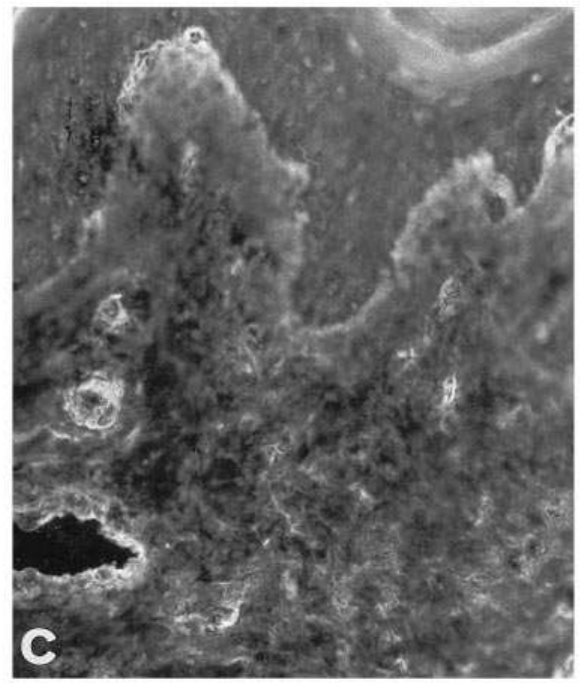

NS

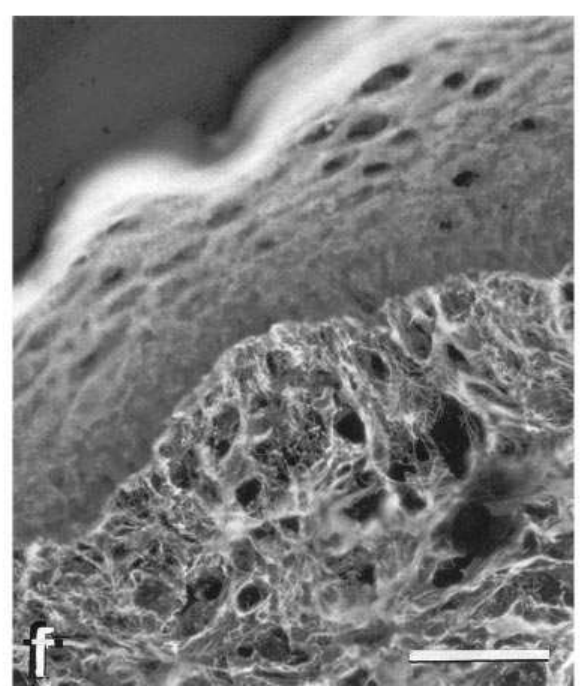

Figure 1. Visualization of transglutaminase activity in normal and regenerating skin after keratinocyte autografting. Transglutaminase activity was detected in skin cryostat sections by incubation with the transglutaminase amine donor MDC in the presence of $\mathrm{Ca}^{2+}$. Incorporation of MDC was visualized using an antidansyl antiserum and fluorescein-conjugated secondary antibodies. (a) Normal skin (NS): MDC is incorporated into the basement membrane and fibrillar connective tissue structures of the dermis. This pattern is consistent with tissue type transglutaminase activity. In contrast, epidermal and keratinocyte transglutaminase activity is visualized in the intercellular space of keratinocytes of the granular and cornified layer. (b) Competition of MDC with putrescine $(M D C+P u)$ prevents dermal and epidermal MDC incorporation to a large extent. (c) In the presence of exogenous tissue transglutaminase (MDC+TGII) MDC incorporation is largely restricted to the DEJ and dermal connective tissue, preferentially the papillary tips, indicating that substrate sites for this enzyme are limited and primarily present in the dermal compartment. (d) $7 \mathrm{~d} \mathrm{pg}$ : while MDC incorporation is prominent in the suprabasal layers of the epidermis and in the deeper zone of the dermis, it is barely visible at the DEJ and the fibroblast-rich infiltrate of the neodermis. $(f)$ MDC incorporation in the presence of exogenous tissue transglutaminase reveals an intensely labeled reticular pattern of connective tissue structures that contain abundant substrate sites which have not been transamidated yet. Tissue transglutaminase shows a clear preference for connective tissue structures in the neodermis including the basement membrane. Epidermal transglutaminase activity appeared elevated in the autografts throughout the regeneration process as indicated by the incomplete competitive inhibition of this enzyme by putrescine ( $b$ and $e$; see also Fig. 2). Bar, $10 \mu \mathrm{m}$.

tinocytes $(12,20)$. Tissue transglutaminase has been implicated in processes as different as GTP-binding in receptor signaling (21) and intracellular cross-linking during programmed cell death (22), but there is increasing evidence for a primary role for tissue transglutaminase in stabilizing extracellular protein assemblies such as collagen fibrils $(4,23)$, microfibrils, ${ }^{2,3}$ the pericellular fibronectin matrix (24), and basement membranes (18). In an attempt to understand the role of tissue trans- glutaminase in the de novo formation of the DEJ, we monitored transglutaminase activity during skin regeneration after transplantation of CEA and demonstrated that anchoring fibrils are stabilized by transglutaminase cross-links.

3. Glanville, R.W., and R.Q. Quian, manuscript submitted for publication. 
MDC
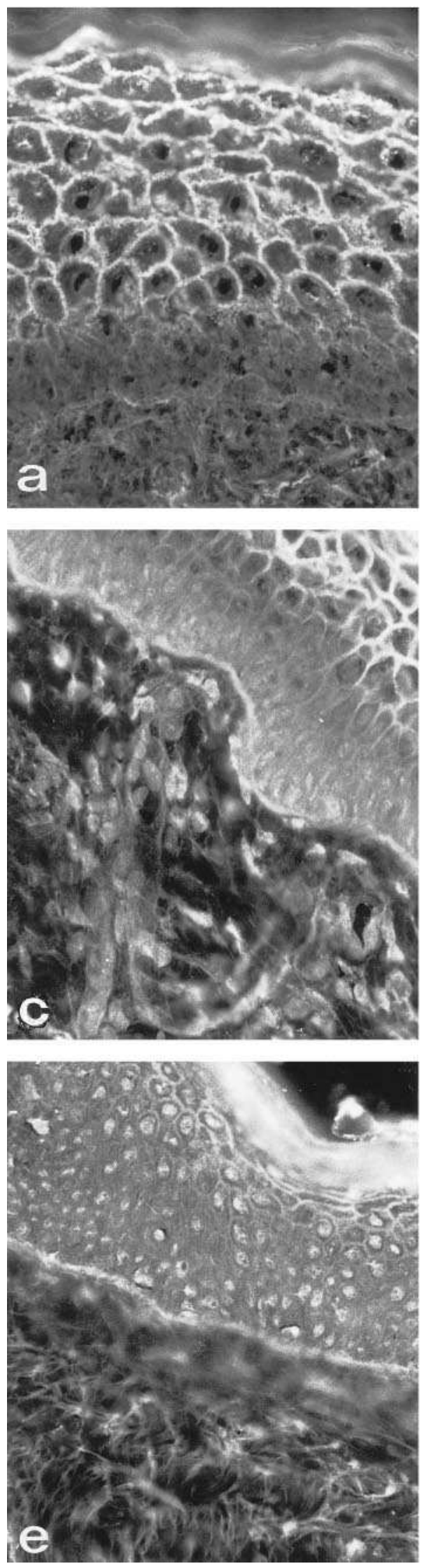

MDC + TGII
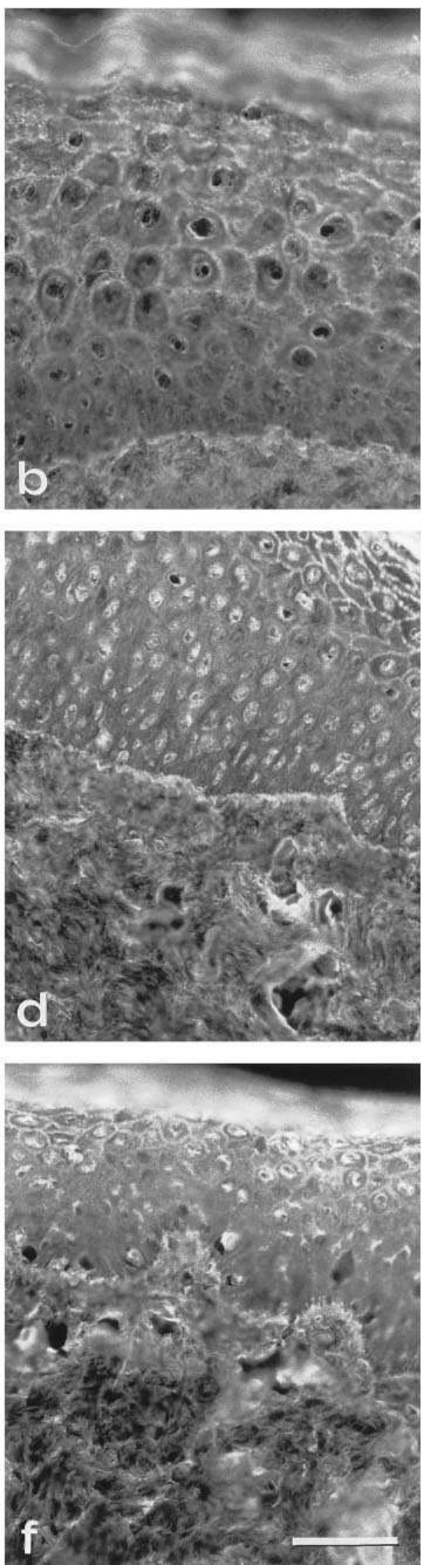

\section{$2 \mathrm{~m}$}

Figure 2. Visualization of transglutaminase activity in advanced keratinocyte autografts. Trans-

$4 \mathrm{~m}$ glutaminase activity was detected on cryostat sections as outlined in Fig. 1. (a) 2 mo pg: MDC incorporation at the DEJ and upper neodermis is still faint. (b) Incubation with MDC in the presence of exogenous transglutaminase $(M D C+$

$T G I I)$ demonstrates the neodermis as an as yet incompletely transamidated target. (c) 4 mo pg: the DEJ expresses full transglutaminase activity. The neodermis shows endogenous transglutaminase activity preferentially associated with capillaries and single cells. (d) Application of tissue transglutaminase highlights potential $17 \mathrm{~m}$ substrate sites in the neodermal connective tissue. (e) $17 \mathrm{mo} \mathrm{pg:}$ MDC incorporation does not differ from that observed with normal skin. $(f)$ Incubation with MDC and purified tissue transglutaminase does not change the staining pattern any more, indicating saturation of potential cross-linking sites. Bar, $10 \mu \mathrm{m}$.

\section{Methods}

Patients. A 5-yr-old girl (R.R.) and a 6-yr-old boy (S.K.) received CEA as primary treatment for burns (full thickness burns of 65 and $62 \%$ of the total body surface area). A 14 -yr-old boy (D.G.) received CEA for post-burn scar revision. In R.R. and S.K., CEA were grafted onto subcutaneous fat after necrosectomy. In D.G., CEA were grafted onto a thin layer of dermal remnants after deep dermabrasion of scarred and hyperpigmented areas in the face and removal of hypertrophic scars at the neck. Scalp biopsies were taken under local anesthesia and CEA sheets were prepared by a commercial laboratory (Biosurface Technology Inc., Boston, MA). For histological fol- 

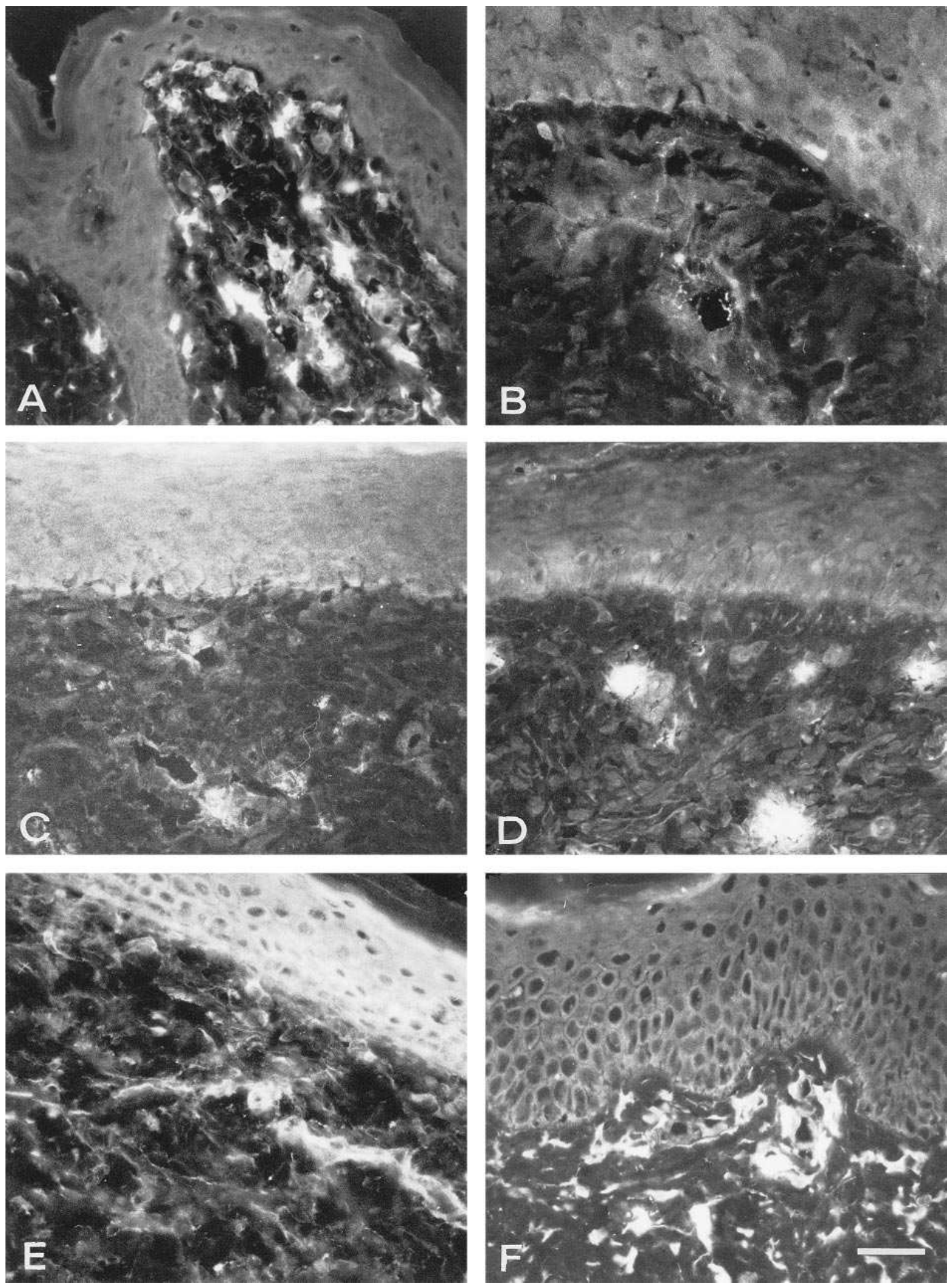

Figure 3. Immunofluorescence localization of Factor XIIIa in normal and regenerating skin after keratinocyte autografting. Factor XIIIa was detected on cryostat sections with antibodies directed to its a-subunit. $(A)$ Normal skin: pericellularly labeled dendritic cells in the papillary dermis are lined up along the DEJ. In addition, Factor XIII-positive cells are associated with papillary capillaries. $(B) 7 \mathrm{~d}$ pg: granular staining of sprouting capillaries. $(C) 6 \mathrm{wk}$ pg: blood vessels and a few pericapillary dendrocytes are positive. $(D) 10 \mathrm{wk}$ pg: patches of Factor XIII-positive cells are evident in the papillary neodermis. $(E) 4$ mo pg: blood vessels are strongly positive and the number of dendritic cells has increased. $(F) 17 \mathrm{mo}$ pg: numerous Factor XIII-positive cells are present in the papillary neodermis with a distribution comparable with normal skin. Bar, $10 \mu \mathrm{m}$. 
low-up, 4-mm punch biopsies were taken during general or local anesthesia, with informed consent of the patients/parents. The biopsies were taken from the left submandibular angle (D.G.), the ventral left thigh (S.K.), and the ventral right thigh (R.R.). Additionally, timematched biopsies from meshed split thickness skin grafts were available in R.R. (dorsal right thigh). Biopsy time points covered days 5-9, 13-14, 21-28, 62-72, and 120-140. In addition, a 17-mo biopsy $(=510$ d) was available in D.G. A time point 0 biopsy was taken in all three children from the wound bed immediately before CEA transplantation. The immunohistological findings were compared with those from normal skin of R.R. and S.K. (normal skin of D.G. was not available), as well as to those obtained with nonwounded skin from eight adult volunteers.

Electron microscopy. Biopsies obtained from R.R. were split, and one-half was used for cryosectioning (see below) the other half was immersed in $4 \%$ glutaraldehyde in $0.1 \mathrm{M}$ sodium-cacodylate for $24-48 \mathrm{~h}$ at $7^{\circ} \mathrm{C}$. Specimens were osmicated, dehydrated, and embedded in EPON 812. Ultrathin sections were viewed with a Philips EM 401 electron microscope at $60 \mathrm{kV}$ (Philips, Enschede, The Netherlands).

Immunohistochemical detection of transglutaminase activity in skin sections. 5- $\mu \mathrm{m}$ cryostat sections from skin biopsies of eight healthy adult volunteers and from CEA were preincubated with $1 \%$ BSA in $0.1 \mathrm{M}$ Tris $/ \mathrm{HCl}, \mathrm{pH} 8.2$, for $30 \mathrm{~min}$ at room temperature
(RT). Transglutaminase activity was detected by subsequent incubation in Tris buffer containing $12 \mu \mathrm{M}$ monodansylcadaverine (MDC) and $5 \mathrm{mM} \mathrm{CaCl}{ }_{2}$ (18). Control sections were incubated with MDC and $2 \mathrm{mM}$ putrescine or MDC and $10 \mathrm{mM}$ EDTA instead of $\mathrm{CaCl}_{2}$. Parallel sections were incubated in the same buffer containing guinea pig liver transglutaminase $(15 \mu \mathrm{g} / \mathrm{ml})$ which had been purified as described (25). Both endogenous and exogenous enzyme reactions were allowed to proceed for $1 \mathrm{~h}$ at RT and then stopped by washing the slides for $5 \mathrm{~min}$ in PBS/10 mM EDTA and two further washes in plain PBS. Incorporated dansyl label was finally detected by incubation for $1 \mathrm{~h}$ at RT with polyclonal antidansyl serum (5). After three washes in PBS, bound antibody was detected with FITC-coupled swine antirabbit IgG (Dako, Hamburg, Germany) diluted 1:30 in PBS for 30 min. Preparations were mounted in Mowiol (Hoechst) prepared in Tris/HCl, pH 8.6. Factor XIII was visualized using an affinity-purified rabbit antibody against the a-subunit (26) diluted 1:100 overnight. The secondary antibody was used as described. Photographs were taken on an HP5 plus film (Ilford Ltd., Basildon, United Kingdom) or Tmax 3200 (Eastman Kodak Co., Rochester, NY) using Polyvar (Reichert-Jung, Heidelberg, Germany) or Axiophot (Zeiss, Jena, Germany) epifluorescence equipment, respectively. For preembedding immunoelectron microscopy, incorporated MDC was detected with primary antibodies as described above and visualized by incubation with
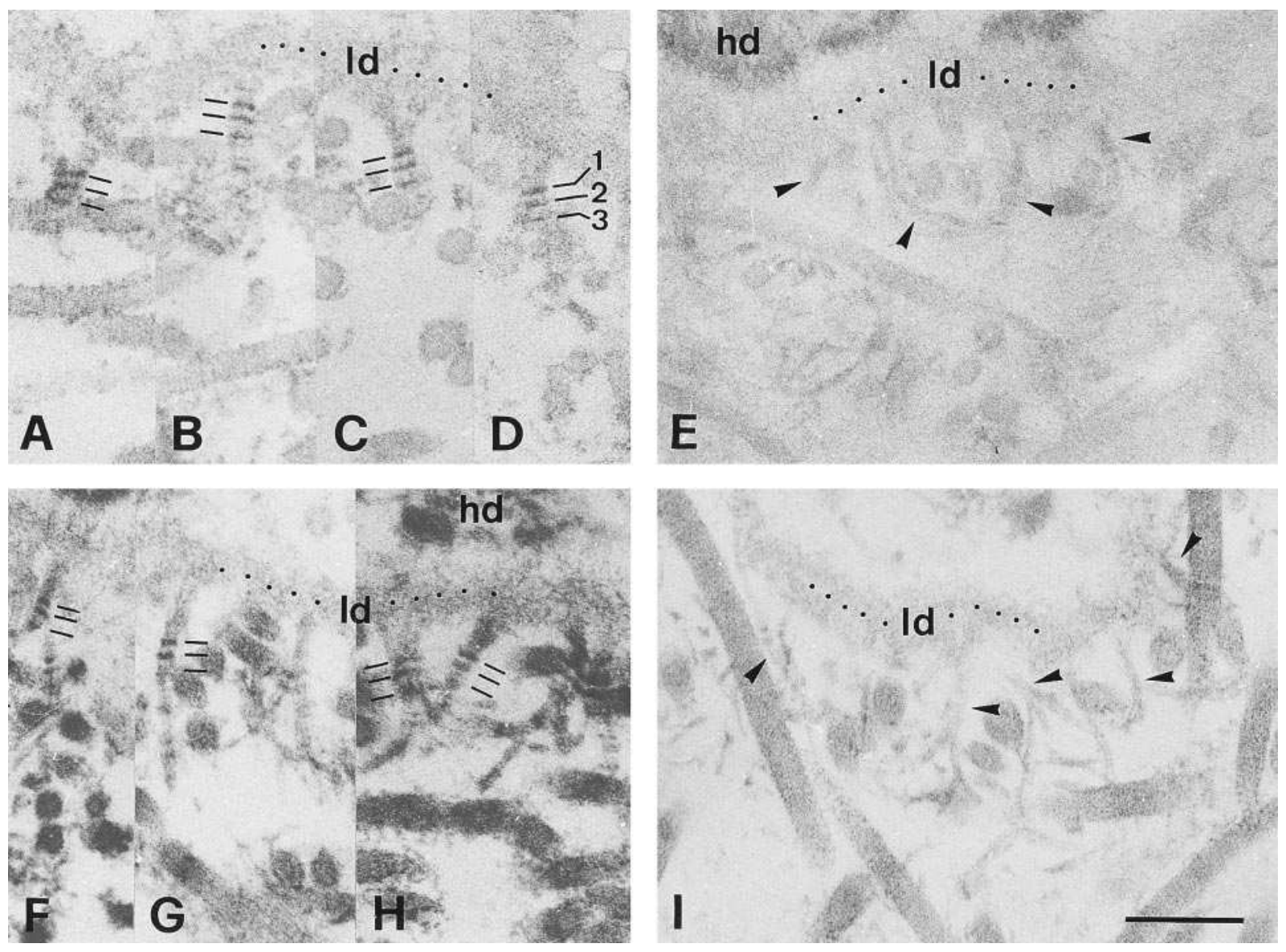

Figure 4. Ultrastructural localization of transglutaminase cross-linking sites on anchoring fibrils in normal skin. Skin cryostat sections were incubated with MDC for $1 \mathrm{~h}$ as in Fig. 1. MDC covalently incorporated into extracellular matrix structures was visualized by indirect immunoperoxidase staining. All electron micrographs show the papillary dermis and the DEJ as characterized by hemidesmosomes (hd) of the basal keratinocytes of the epidermis and the lamina densa $(l d)$ of the basement membrane. $(A-E)$ ultrathin sections were counterstained with lead citrate only. $(A-D)$ Transglutaminase cross-linking sites are visualized as three major bands (dashes) on individual anchoring fibrils. ( $E$ ) Inhibition of the transglutaminase by EDTA prevents cross-linking of MDC to anchoring fibrils (arrowheads). ( F-I) Additional light counterstain with uranyl acetate enhances contrast and highlights the striation pattern on anchoring fibrils obtained with the antidansyl antibodies. (I) Inhibition of transglutaminase with EDTA abolishes dansyl immunostaining on anchoring fibrils. Bars, $100 \mathrm{~nm}$. 

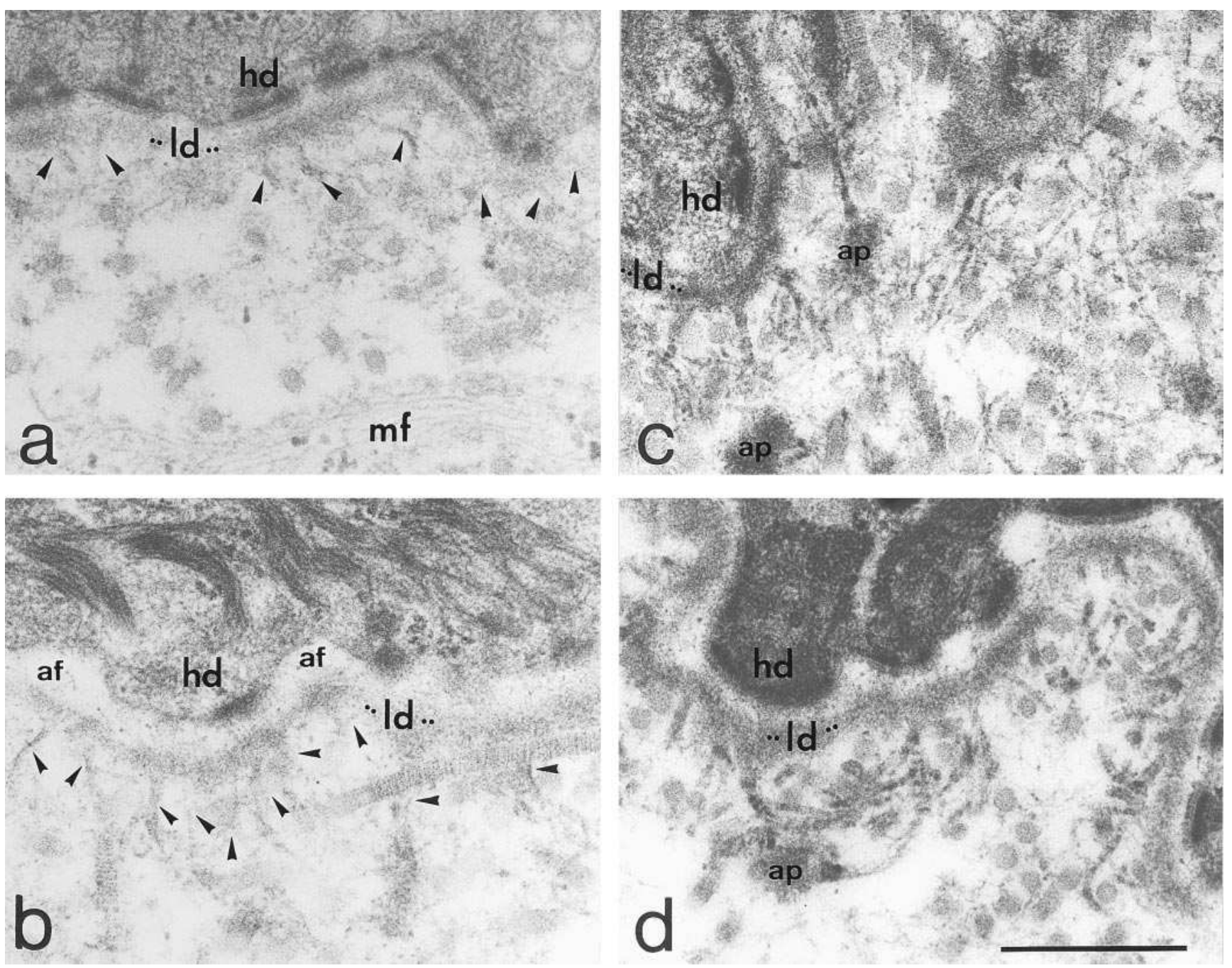

Figure 5. Development of anchoring fibrils in keratinocyte autografts. (a) $1 \mathrm{mo} \mathrm{pg}$ : the lamina densa ( $l d$ ) is continuous; thin anchoring fibrils ( $a f$ ) (arrowheads) are visible opposite to hemidesmosomes $(h d)$. The collagen fibers of the papillary dermis are loosely packed. Bundles of 10-12-nm microfibrils ( $m f)$ are present. (b) 2 mo pg: more and thicker anchoring fibrils are detectable. (c) 4 mo pg: anchoring fibrils are abundant, have gained thickness, and display cross-striation. Also, anchoring plaques (ap) are detectable. (d) Normal skin obtained from a meshed split skin graft of the same patient (R.R.) shows normal distribution and size of anchoring fibrils. Ultrathin sections were fully counterstained with uranyl acetate and lead citrate. Bar, $100 \mathrm{~nm}$.

a peroxidase-conjugated goat anti-rabbit secondary antibody (Jackson Laboratories, Bar Harbor, ME) 1:100 in PBS for 30 min at RT. After fixation in $2.5 . \%$ glutaraldehyde for $30 \mathrm{~min}$ at RT, the peroxidase reaction was developed with $0.1 \%$ diaminobenzidine tetrahydrochloride (Fluka, Buchs, Switzerland) in $0.1 \mathrm{M}$ Tris $/ 5 \%$ sucrose, $\mathrm{pH} 7.5$, in the presence of $0.03 \%$ hydrogen peroxide (27). Sections were processed for electron microscopy as described except that ultrathin sections were counterstained with lead citrate only.

Identification of collagen VII as a substrate for purified tissue transglutaminase. The triple helical domain of human collagen VII was isolated by limited pepsin digestion of human placental tissue extracts as described previously (28) and $0.5-\mathrm{ml}$ aliquots were precipitated with ethanol and the pellets were dissolved in $0.1 \mathrm{M}$ Tris/ $/ 0.4 \mathrm{M}$ $\mathrm{NaCl}, \mathrm{pH} 8.3$, and incubated overnight at $37^{\circ} \mathrm{C}$ with $250 \mu \mathrm{Ci}$ of $\left[{ }^{3} \mathrm{H}\right]$ putrescine (Du Pont/New England Nuclear, Boston, MA) and $8 \mu \mathrm{g}$ of purified tissue transglutaminase and $5 \mathrm{mM} \mathrm{CaCl}_{2}$ in the presence or absence of $20 \mathrm{mM}$ EDTA. A recombinant NC-2 fragment representing the carboxy terminus of procollagen VII was expressed as a bacterial fusion protein as described elsewhere (29). Approximately $10 \mu \mathrm{g}$ of the recombinant protein was dissolved in $0.1 \mathrm{M}$ Tris/
$0.4 \mathrm{M} \mathrm{NaCl}, \mathrm{pH} 8.3$, and incubated for $17 \mathrm{~h}$ as described in the presence or absence of EDTA. In parallel, $20 \mu \mathrm{g}$ of purified fibronectin (Sigma Immunochemicals, St. Louis, MO) was used as a positive control. Incubation was terminated by precipitation of proteins with methanol/chloroform (30). Pellets were resuspended in SDS-PAGE sample buffer and proteins were separated by SDS-PAGE under reducing conditions in a $4.5-15 \%$ polyacrylamide gel and transferred onto nitrocellulose. Immunoblotting was carried out with affinitypurified domain-specific collagen VII antibodies as described (28, 29). After development of the blot, each lane was cut into 2-mm slices which were presolved in $100 \mu \mathrm{l}$ of dimethylformamide in liquid scintillation vials. Finally, $2 \mathrm{ml}$ of scintillant (Lumasafe Plus, Lumac, Groningen, The Netherlands) was added and radioactivity was determined.

\section{Results}

Transglutaminase activity in normal human skin. To detect endogenous transglutaminase activity, cryostat sections of human 
skin were incubated with MDC, a potent amine donor substrate for transglutaminase, and covalently attached dansyl epitopes (through enzymatic activity) were subsequently visualized with specific antibodies. It has been shown that the pattern of MDC incorporation on tissue sections correlates well with the distribution of active transglutaminase in situ $(5,18)$. In normal human skin (Fig. $1 a$ ), MDC incorporation was detected along the DEJ which is known to contain transglutaminase cross-links $(4,18)$ and in differentiating epidermis (presumably representing keratinocyte and epidermal transglutaminase activity) $(12,13)$. MDC incorporation was also observed in the microfibrillar apparatus of the papillary dermis and surrounding papillary capillaries, which is in concert with earlier observations that tissue transglutaminase is expressed by dermal fibroblasts ${ }^{2}$ (19) and vascular endothelia (31). Incubation with MDC in the presence of an 80-fold excess of putrescine, a competitive substrate to MDC, prevented incorporation of MDC to a large extent (Fig. $1 \mathrm{~b}$ ), whereas sections incubated with MDC in the presence of EDTA (transglutaminases are calcium dependent) showed no incorporation of MDC (results not shown). Supplementing the reaction mixture with purified tissue transglutaminase led to preferential incorporation of MDC into the DEJ and connective tissue of the papillary dermis (Fig. 1c). This localized the preferential target proteins for tissue transglutaminase in skin.

Transglutaminase activity in regenerating skin after transplantation of CEA. Transglutaminase activity was detected as described for normal skin on cryosections from skin biopsies obtained at different time points ( $7 \mathrm{~d}$, and 2, 4, and $17 \mathrm{mo}$ ) after grafting. The pattern of proteins cross-linked by endogenous transglutaminase in the dermis was markedly altered (Fig. $1 d$ and Fig. 2) and did not appear normal until $17 \mathrm{mo} \mathrm{pg}$ (Fig. $2 e$ ). The amount of MDC cross-linked to structures in the DEJ was low during the first 2 mo pg (Fig. $1 d$ and Fig. 2). Extensive cross-linking at the DEJ was appreciable after 4 mo (Fig. 2 c) and the pattern appeared normal after 17 mo pg (Fig. $2 e$ ) when compared with normal skin (Fig. $1 a$ ). The neodermis was dominated during the first 4 wk by a fibroblast-rich infiltrate which expressed transglutaminase activity (Fig. $1 d$ ). The pattern of MDC incorporation was initially dominated by cell-bound transglutaminase activity in the cellrich infiltrate, but became gradually substituted by a more
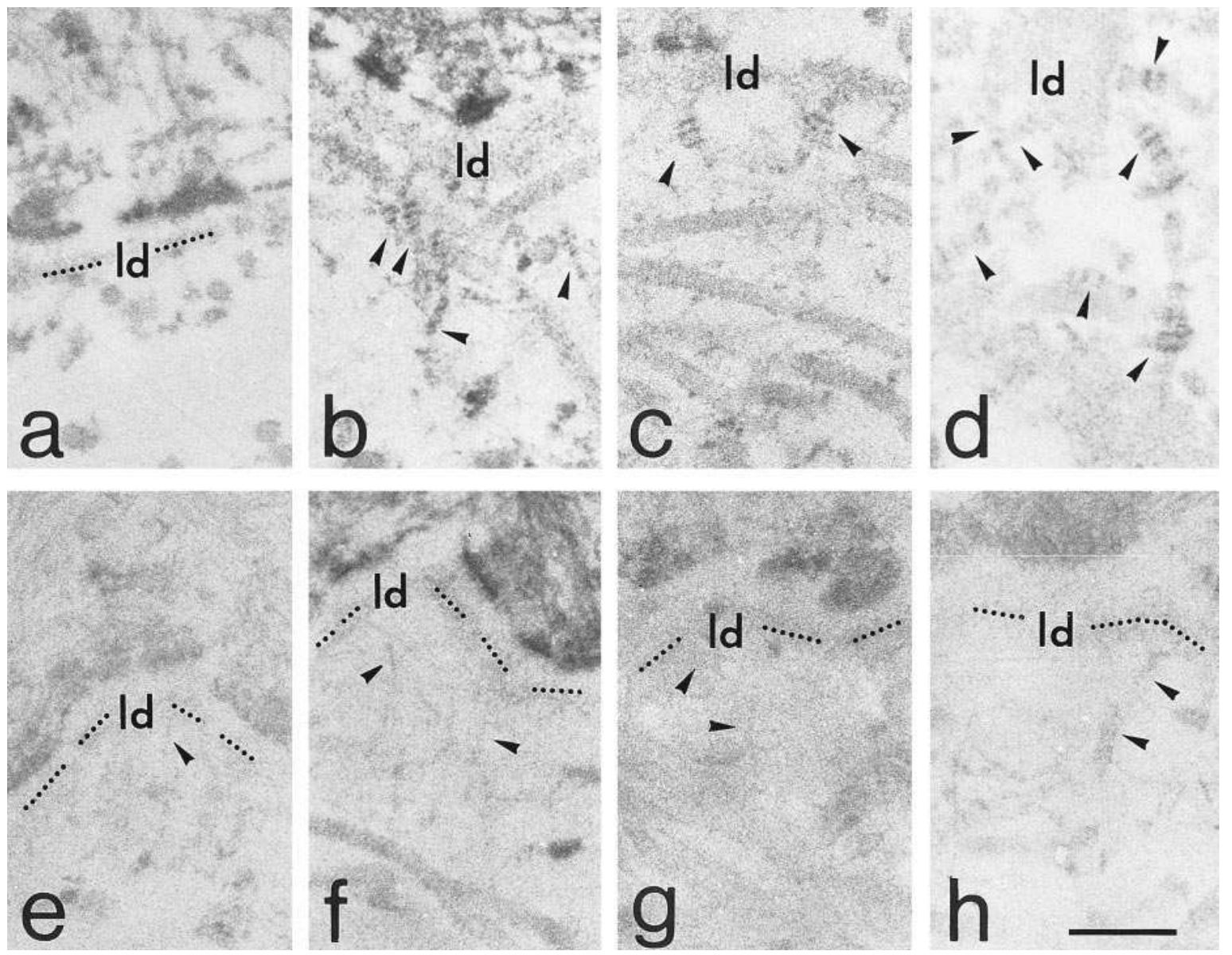

Figure 6. Immunoelectron microscopic localization of transglutaminase cross-links on anchoring fibrils of regenerating and meshed split normal skin from the same patient. Transglutaminase activity was visualized as described in Fig. 4. Ultrathin sections were counterstained with lead citrate only. (a) $1 \mathrm{mo} \mathrm{pg:} \mathrm{transamidation} \mathrm{of} \mathrm{anchoring} \mathrm{fibrils} \mathrm{is} \mathrm{not} \mathrm{detectable,} \mathrm{although} \mathrm{first} \mathrm{thin} \mathrm{anchoring} \mathrm{fibrils} \mathrm{are} \mathrm{present} \mathrm{at} \mathrm{this} \mathrm{stage.} \mathrm{(b)} 2$ mo pg: the MDC incorporation is detectable on anchoring fibrils. (c) $4 \mathrm{mo} \mathrm{pg}$, anchoring fibrils display a three-band pattern at the central portion, also the lateral aspect of collagen fibrils is decorated with MDC-positive patches. $(d)$ Normal skin from a meshed split skin graft: thick anchoring fibrils are present which show a two- or three-band pattern of transamidation. ( $e-h$ ) Control experiments (corresponding to $a-d$, respectively): incubation of the cryostat section with MDC in the presence of EDTA causes complete absence of dansyl-positive structures. Bar, $100 \mathrm{~nm}$. 
A

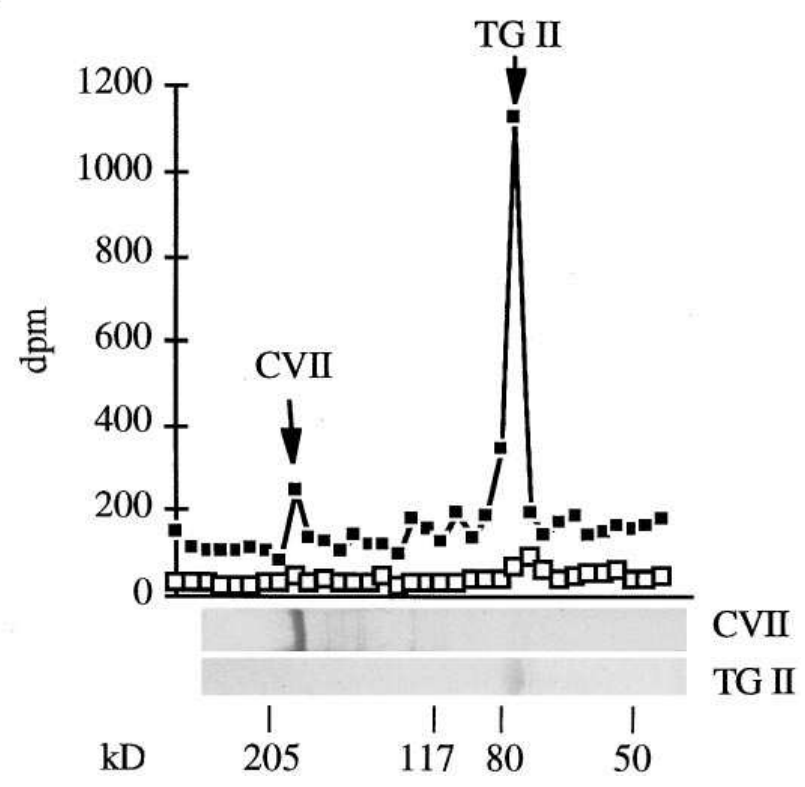

B

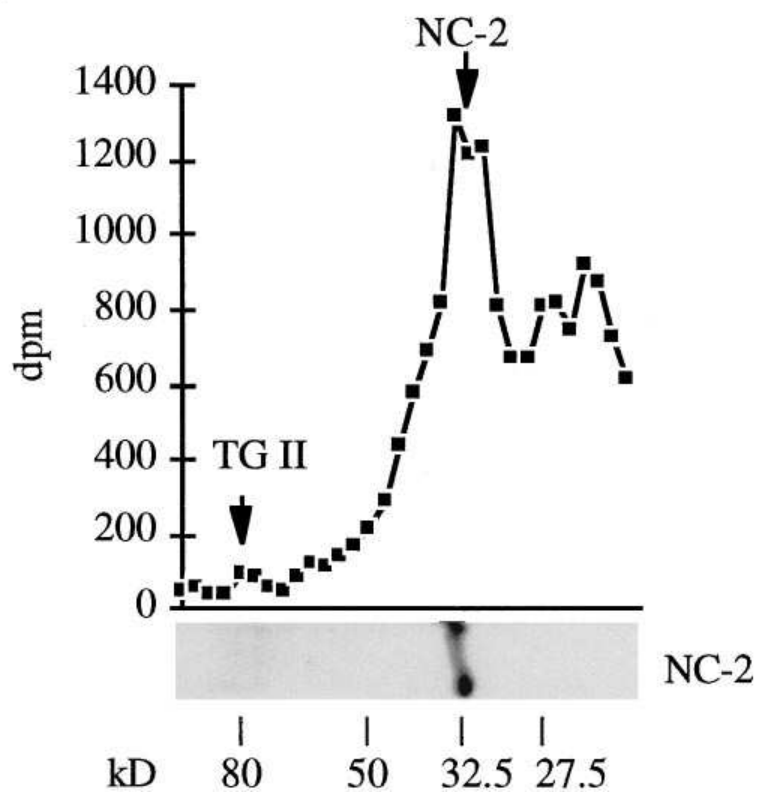

Figure 7. Transamidation of collagen VII by tissue transglutaminase. The triple helical domain $(A)$ and the NC-2 domain $(B)$ of human collagen VII were incubated with purified tissue transglutaminase and the amine donor $\left[{ }^{3} \mathrm{H}\right]$ putrescine in the presence (closed symbols) or absence (open symbols) of EDTA. Proteins were separated by SDS-PAGE with a 4-15\% polyacrylamide gel, transferred onto nitrocellulose, and detected with specific antibodies (on duplicate lanes). Immunoblot strips were cut in slices and analyzed for ${ }^{3} \mathrm{H}-$ label to compare distribution of the radioactivity with the migration of immunologically identified proteins. Migration of molecular mass standards is indicated on the bottom of each panel. $(A)$ The triple helical domain is a poor amine acceptor substrate in comparison to the enzyme which shows extensive autotransamidation. $(B)$ The recombinant NC-2 domain is an excellent amine acceptor substrate and competes efficiently with the autotransamidation of the enzyme. The radioactivity seen between 20 and $25 \mathrm{kD}$ probably reflects incorporation of $\left[{ }^{3} \mathrm{H}\right]$ putrescine into small bacterial proteins contaminating the recombinant NC-2 domain preparation. CVII, triple helical domain of collagen VII; $N C$-2, carboxy-terminal, noncollagenous domain of collagen VII; $T G I I$, tissue transglutaminase.

web-like pattern characteristic of fibrillar structures in the extracellular compartment (Fig. $2 e$ ). In the presence of purified tissue transglutaminase, MDC was extensively cross-linked to a network of fibrils in the neodermis $7 \mathrm{~d}$ pg and later (Fig. $1 f$ and Fig. 2, $b$ and $d$ ), which was not evident after visualization of endogenous transglutaminase activity. This shows that numerous target sites for cross-linking by transglutaminase are available in the newly deposited matrix, indicating that crosslinking of ECM structures is a slow process and primarily not limited by the amount of ECM proteins available. Normal levels of cross-linking were reached 17 mo pg since the MDC incorporation pattern resembled the pattern in normal skin. Furthermore, inclusion of exogenous tissue transglutaminase in the reaction did not change the pattern significantly, indicating saturation of cross-linking sites in the matrix (Fig. $2 f$ ). To assess the contribution of the plasma transglutaminase Factor XIIIa (FXIII) to the dansyl incorporation, we directly immunolocalized the a-subunit of FXIII in normal and regenerating skin (Fig. 3). As described recently (32), FXIII was associated in normal skin mostly with dendritic cells and blood vessels in the dermis. In regenerating skin, FXIII+ blood vessels were seen early after grafting (Fig. $3 B$ ), whereas FXIII+ dendritic cells appeared sparsely in the papillary neodermis during the first 2 mo pg (Fig. 3, $C$ and $D$ ). Expression of FXIII on blood vessels was comparable with normal 4 mo pg (Fig. 3 $E$ ) but the overall population density of FXIII+ cells including dendritic cells reached a distribution similar to normal skin only after 17 mo (Fig. 3 F). Neither normal nor regener- ating skin showed Factor XIIIa associated with connective tissue elements including the DEJ, except for the excision margins of the biopsies where some bleeding had occurred.

Transglutaminase-mediated cross-links are present on anchoring fibrils of the DEJ of normal skin. To analyze the targets for the cross-linking at the DEJ, incorporated MDC was detected on skin sections with specific antibodies and peroxidase-conjugated secondary antibodies and then visualized by electron microscopy. MDC incorporation was detected as three horizontal bands on the central portions of anchoring fibrils indicating transglutaminase cross-linking at these sites (Fig. 4). MDC was also detected on microfibrils and fibrillar collagens as reported in a previous study (data not shown).

Transglutaminase cross-linking of de novo forming anchoring fibrils in keratinocyte autografts follows their assembly with a time lag. Thin anchoring fibrils were regularly observed in regenerating skin $1 \mathrm{mo} \mathrm{pg}$ (Fig. $5 a$ ) and appeared to increase in number and thickness after 2 mo pg (Fig. $5 b$ ). The development of anchoring fibrils with a cross-striated central portion and the appearance of anchoring plaques took 4 mo (Fig. $5 c$ ). In comparison to normal skin from the same patient (Fig. $5 d$ ), the anchoring fibrils still appeared thinner, and possibly more numerous. When the incorporation of MDC was studied by immunoelectron microscopy, no label could be identified on anchoring fibrils $1 \mathrm{mo}$ pg (Fig. 6, $a$ and $e$ ) although these structures were morphologically apparent. Anchoring fibrils became positive for MDC incorporation 2 mo pg (Fig. 6, $b$ and $f$ ) and the staining pattern did not change significantly thereafter 
except for increased thickness of anchoring fibrils after 4 mo (Fig. 6, $c$ and $g$ ). The pattern of the cross-linking in three horizontal bands was comparable with that of normal anchoring fibrils (Fig. 6, $d$ and $h$ ) and seemingly occurred at all three sites at the same time.

Collagen VII acts as an amine acceptor in tissue transglutaminase-catalyzed cross-linking. To obtain further information on the cross-linking of anchoring fibrils by tissue transglutaminase, we investigated whether different domains of collagen VII serve as amine acceptor substrates for tissue transglutaminase in vitro. Therefore, the triple helical domain of collagen VII, isolated from human placenta by limited pepsin digest, and the recombinant carboxy-terminal NC-2 domain were incubated with tissue transglutaminase and $\left[{ }^{3} \mathrm{H}\right]$ putrescine in the presence of calcium. This resulted in modest incorporation of the amine donor substrate into the collagenous collagen VII domain and strong autocatalytic labeling of the enzyme (Fig. 7 $A$ ). In contrast, the recombinant NC-2 domain proved to be an excellent amine acceptor substrate effectively competing with autotransamidation of the enzyme (Fig. $7 \mathrm{~B}$ ). No incorporation of $\left[{ }^{3} \mathrm{H}\right]$ putrescine was obtained when transglutaminase activity was inhibited by EDTA (Fig. $7 A$ ). Preliminary data with a recombinant $\mathrm{NC}-2$ domain expressed in eukaryotic cells confirmed these findings (data not shown).

\section{Discussion}

This study provides evidence that skin regenerating from keratinocyte autografts is substantially cross-linked by transglutaminase in a time-dependent fashion. However, this process takes $\sim 1.5 \mathrm{yr}$ for the dermis and $\sim 4$ mo for the DEJ to reach a degree which is comparable with normal skin. Remarkably, the time lag of transglutaminase cross-linking of the DEJ coincides with our experience that the attachment of keratinocyte autografts is particularly unstable for the first 2 mo pg (Gobet, R., S. Altermatt, C. Meuli-Simmen, M. Raghunath, M. Benathan, A. Dietl, and M. Meuli, manuscript submitted for publication). This is clinically evident by the formation of mechanically induced blisters which can result in substantial loss of transplanted material. Furthermore, subclinical blistering can be found during histological examinations of these grafts, ${ }^{3}$ a common feature also seen in heritable skin disorders with a defective DEJ (3). However, blistering ceases after this critical period and does not reoccur at any later time point. ${ }^{3}$ We found that transglutaminase activity along the DEJ is remarkably low during this critical period, indicating that transglutaminase cross-linking might be a crucial factor for the stability of the DEJ. In fact, the ultrastructural analysis of normal skin revealed transamidation of anchoring fibrils, the structures crucial for dermo-epidermal cohesion (2). However, in keratinocyte autografts we did not observe cross-linking of MDC to anchoring fibrils before 2 mo pg, although anchoring fibrils were consistently found in ultrastructural studies already 1 mo pg. Interestingly, the appearance of transglutaminase cross-links on anchoring fibrils coincided with the clinical stabilization of the grafts.

Three distinct regions on the central portion of anchoring fibrils were identified as targets for transglutaminase crosslinking. This central portion is known to contain the triple helical domains and the carboxy-terminal telopeptides of antiparallely aligned collagen VII molecules (2). This region also contains a part of the carboxy-terminal noncollagenous NC-2 do- main that is retained after removal of a carboxy-terminal propeptide from the procollagen VII molecule (29). As depicted in Fig. 8, dimer formation leads to an antiparallel overlap of the carboxy termini of collagen VII molecules. Our biochemical data suggest that the triple helical region of collagen VII is a weak and the NC-2 domain a very attractive glutaminyl substrate for tissue transglutaminase. In fact, the NC-2 domain contains four glutamine residues proximal to the putative cleavage site (29), whereas the histidine tag of the recombinant fusion proteins contains none. The distinct pattern of transglutaminase cross-linking sites on anchoring fibrils raises the question of the partners involved in this process. Potentially, collagen VII as the major if not the sole structural component of anchoring fibrils (2) would be able to form homopolymers stabilized by intermolecular $\gamma$-glutamyl- $\epsilon$-lysine cross-links. It is conceivable that in the antiparallel overlap model of two collagen VII molecules the trimmed NC-2 domain as amine ac-

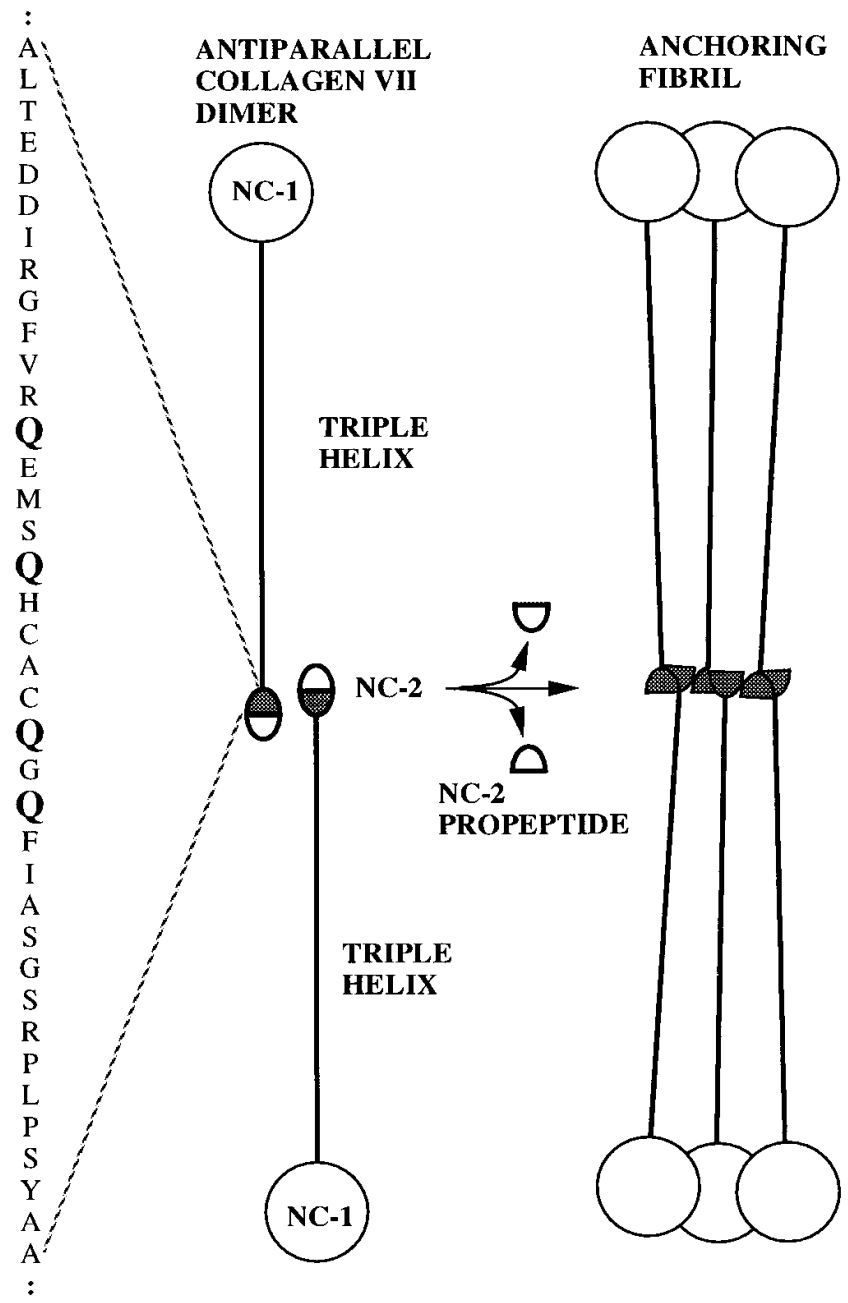

Figure 8. Schematic representation of the current model for the assembly of procollagen VII resulting in the formation of anchoring fibrils. Procollagen VII molecules align in an antiparallel fashion and propeptides from either NC-2 domain are removed. The amino acid sequence of one remaining NC-2 domain (shaded area) is given on the left in single letter code. Glutamine residues as potential donor substrates for transglutaminase cross-linking are highlighted (boldface). The different regions of the molecule are not drawn to scale, the overlap region is hypothetical. 
ceptor substrate would face an amine donor. It remains to be shown whether the triple helical domain, a poor amine acceptor substrate, might be a good amine donor substrate. In fact, there would be several lysyl residues available in the carboxyterminal triple helical region and the NC-2 domain itself. It should also be noted that the triple helical domain of collagen VII contains a fibronectin binding site (33). Fibronectin in turn is an excellent substrate for tissue transglutaminase (34-37) and might become cross-linked to anchoring fibrils, as may other hitherto unidentified proteins.

The occurrence of transglutaminase cross-linking sites only on anchoring fibrils with a certain degree of maturity could also be a reflection of the regulation of transglutaminase activity in regenerating skin. In fact, a potential regulation of the cross-linking by limited secretion of transglutaminases has been suggested by several studies (for review see reference 9). It has been demonstrated that overexpression of tissue transglutaminase does not necessarily lead to increased cross-link formation $(38,39)$. This suggests that transglutaminases are present in an inactive form in an intracellular pool from which they are slowly released (40). Our observation of mainly cellassociated transglutaminase activity during the first 4 mo of regeneration in the papillary dermis might therefore point toward the same direction. Our attempts to directly immunolocalize tissue transglutaminase with antibodies raised against the guinea pig enzyme failed because of their very limited cross-reactivity with the human enzyme. Since dermal fibroblasts ${ }^{2}$ (19) and basal keratinocytes $(12,20)$ both have been shown to express tissue transglutaminase, it appears likely that this enzyme is acting on the DEJ. However, we cannot completely exclude that a part of the cell-associated transglutaminase activity might be attributable to FXIII+ cells. However, FXIII+ perivascular dendritic cells that were mostly located in the reticular dermis during the first 4 mo showed a normal distribution pattern in the papillary dermis only $17 \mathrm{mo}$ pg. These results are in agreement with previous findings for postburn dermis (31). In contrast, transglutaminase (keratinocyte and epidermal transglutaminase) activity in the neoepidermis was high at all stages of skin regeneration and the pattern consistent with the formation of cornified cell envelopes.

Human skin represents a complex system of extracellular matrix proteins serving different biological tasks. Two different transglutaminases have been found to play a role in the terminal differentiation of epidermal keratinocytes in order to form a protective barrier represented by the stratum corneum (for reviews see references 9, 12,13). Tissue transglutaminase is operative at the $\operatorname{DEJ}(4,18)$ and underlying dermal structures, particularly the microfibrillar apparatus. ${ }^{2}$ This highlights a functional partnership between molecules designed to convey integrity and shape to a particular tissue and members of the transglutaminase family which are highly efficient biological glues $(9,41,42)$. In fact, many studies support this function of transglutaminases in wound healing situations. It has been reported that the topical treatment of incisional skin wounds with putrescine, resulting in competitive inhibition of transglutaminase cross-linking, causes decreased wound breaking strength (43). Furthermore, the systemic administration of MDC or spermidine, also competitive inhibitors of transglutaminase cross-linking, decreases healing of gastric and duodenal stress ulcers (44). Hence, it is tempting to speculate that the external application of purified or recombinant tissue transglutaminase might accelerate the formation of a stable
DEJ and underlying dermis not only in keratinocyte autografts but also in other wound healing situations. The use of tissue transglutaminase in the experimental repair of the rat optic nerve (45) or articular cartilage (Juergensen, K., D. Aeschlimann, V. Cavin, M. Genge, and E.B. Hunziker, manuscript submitted for publication) has been reported. Therefore, tissue transglutaminase seems to be a promising representative of an ancient biological principle in the quest for a therapeutic cross-linker of extracellular matrix proteins.

\section{Acknowledgments}

We are indebted to Nicole Mühlheim, L. Burger, and Susanne Staubli for the art work. We thank Ms. Müller and Ms. Scherrer-Hertrich (Department of Dermatology, University of Zürich) and Ms. Ulrike Keller and Ms. Andrea Wissel for the preparation of cryostat sections. We are very grateful for the generous support of Dr. T. Bächi (Central Electron Microscopy Laboratory, University of Zürich). Dr. Kohfeld, Institute for Biochemistry, Martinsried, generously made the eukaryotically expressed NC-2 domain available to us.

This work was supported by grants from the Swiss National Science Foundation $(32-27884.89 / 1+2)$ to B. Steinmann, and the Deutsche Forschungsgemeinschaft (DFG) Ra 447/3-1 and Ra 447/3-2 to M. Raghunath, and Br 1475/3-1 to L. Bruckner-Tuderman. D. Aeschlimann is supported by an EMBO Long Term Fellowship (ALTF 971994).

\section{References}

1. Compton, C.C., J.M. Gil, D.A. Bradford, S. Regauer, G.G. Gallico, and N.E. O'Connor. 1989. Skin regenerated from cultured epithelial autografts on full-thickness burn wounds from 6 days to 5 years after grafting. Lab. Invest. 60 : 600-612.

2. Burgeson, R.E. 1993. Type VII collagen, anchoring fibrils and epidermolysis bullosa. J. Invest. Dermatol. 101:252-255.

3. Bruckner-Tuderman, L. 1993. Epidermolysis bullosa. In Connective Tissue and Its Heritable Disorders. Molecular, Genetic and Medical Aspects. P.M. Royce and B. Steinmann, editors. Wiley-Liss, New York. 507-531.

4. Aeschlimann, D., O. Kaupp, and M. Paulsson. 1995. Osteonectin is a major glutaminyl substrate for transglutaminase-catalyzed cross-linking in cartilage matrix. J. Cell Biol. 129:881-892.

5. Aeschlimann, D., A. Wetterwald, H. Fleisch, and M. Paulsson. 1993. Expression of tissue transglutaminase in skeletal tissues correlates with events of terminal differentiation of chondrocytes. J. Cell Biol. 120:1461-1470.

6. Aeschlimann, D., M. Paulsson, and K. Mann. 1992. Identification of $\mathrm{Gln}^{726}$ in nidogen as the amine acceptor in transglutaminase c $_{\mathrm{c}}$-catalyzed crosslinks of laminin-nidogen complexes. J. Biol. Chem. 267:11316-11321.

7. Hohenadl, C., K. Mann, U. Mayer, R. Timpl, M. Paulsson, and D. Aeschlimann. 1995. Two adjacent N-terminal glutamines of BM-40 (osteonectin, SPARC) act as amine acceptor sites in transglutaminase-catalyzed modification. J. Biol. Chem. 270:23415-23420.

8. Gallico, G.G., N.E. O'Connor, C.C. Compton, O. Kehinde, and H.A. Green. 1984. Permanent coverage of large burn wounds with autologous cultured human epithelium. N. Engl. J. Med. 311:448-451.

9. Aeschlimann, D., and M. Paulsson. 1994. Transglutaminases: protein cross-linking enzymes in tissues and body fluids. Thromb. Haemostasis. 71:402415 .

10. Folk, J.E., and J.S. Finlayson. 1977. The $\epsilon$-( $\gamma$-glutamyl)lysine cross-link and the catalytic role of transglutaminases. Adv. Protein Chem. 31:1-133.

11. Lorand, L., and S.M. Conrad. 1984. Transglutaminases. Mol. Cell. Biochem. 58:9-35.

12. Kim, S.Y., S.-L. Chung, and P.M. Steinert. 1995. Highly active soluble processed forms of the transglutaminase 1 enzyme in epidermal keratinocytes. J. Biol. Chem. 270:18026-18035.

13. Kim, I.-G., J.J. Gorman, S.-C. Park, S.-I. Chung, and P. Steinert. 1993. The deduced sequence of the novel protransglutaminase E (TGase3) of human and mouse. J. Biol. Chem. 268:12682-12690.

14. Steinert, P.M., and L.N. Marekov. 1995. The proteins elafin, filaggrin, keratin intermediate filaments, loricrin and small proline-rich proteins 1 and 2 are isodipeptide cross-linked components of the human epidermal cornified cell envelope. J. Biol. Chem. 270:17702-17711.

15. Russell, L.J., J.J. DiGiovanna, N. Hashem, J.G. Compton, and S.J. Bale. 1994. Linkage of autosomal recessive lamellar ichthyosis to chromosome 14q. Am. J. Hum. Genet. 55:1146-1152. 
16. Huber, M., I. Rettler, K. Bernasconi, E. Frenk, S.P.M. Lavrijsen, M. Ponec, M.A. Bon, S. Lautenschlager, D.F. Schorderet, and D. Hohl. 1995. Mutations of the keratinocyte transglutaminase in lamellar ichthyosis. Science (Wash. DC). 267:525-528.

17. Thomazy, V., and L. Fesus. 1989. Differential expression of tissue transglutaminase in human cells. Cell Tissue Res. 225:215-224.

18. Aeschlimann, D., and M. Paulsson. 1991. Cross-linking of lamininnidogen complexes by tissue transglutaminase. A novel mechanism for basement membrane stabilization. J. Biol. Chem. 266:15308-15317.

19. Upchurch, H., E. Conway, M.K. Patterson, and M.D. Maxwell. 1991. Localization of cellular transglutaminase on the extracellular matrix after wounding: characteristics of the matrix bound enzyme. J. Cell. Physiol. 149:375382.

20. Lichti, U., T. Ben, and S.H. Yuspa. 1985. Retinoic acid-induced transglutaminase in mouse epidermal cells is distinct from epidermal transglutaminase. J. Biol. Chem. 260:1422-1426.

21. Nakaoka, H., D.M. Perez, K.J. Baek, T. Das, A. Husain, K. Misono, M.-J. Im, and R.M. Graham. 1994. Gh: a GTP-binding protein with transglutaminase activity and receptor signaling function. Science (Wash. DC). 264:1593-1596.

22. Fesus, L., P.J.A. Davies, and M. Piacentini. 1991. Apoptosis: molecular mechanisms in programmed cell death. Eur. J. Cell Biol. 56:170-177.

23. Kleman, J.-P., D. Aeschlimann, M. Paulsson, and M. van der Rest. 1995. Transglutaminase-catalyzed cross-linking of fibrils of collagen V/XI in A204 rhabdomyosarcoma cells. Biochemistry. 34:13768-13775.

24. Martinez, J., D.G. Chalupowicz, R.K. Roush, A. Sheth, and C. Barsigian. 1994. Transglutaminase-mediated processing of fibronectin by endothelial cell monolayers. Biochemistry. 33:2538-2545.

25. Connellan, J.M., S.I. Chung, N.K. Whetzel, L.M. Bradley, and J.E. Folk. 1971. Structural properties of guinea pig liver transglutaminase. J. Biol. Chem. 246:1093-1098.

26. Barry, E.L.R., and D.F. Mosher. 1990. Binding and degradation of blood coagulation factor XIII by cultured fibroblasts. J. Biol. Chem. 265:93029307.

27. König, A., M. Raghunath, B. Steinmann, and L. Bruckner-Tuderman. 1994. Dominant dystrophic epidermolysis bullosa: intracellular accumulation of collagen VII in keratinocytes leads to reduced number of anchoring fibrils and skin blistering. J. Invest. Dermatol. 102:105-110.

28. Bruckner-Tuderman, L., U.W. Schnyder, K.W. Winterhalter, and P. Bruckner. 1987. Tissue form of type VII collagen from human skin and fibroblasts in culture. Eur. J. Biochem. 165:607-611.

29. Bruckner-Tuderman, L., O. Nilssen, D. Zimmermann, M.-T. DoursZimmermann, U.D. Kalinke, T. Gedde-Dahl, Jr., and J.-O. Winberg. 1995. Immunohistochemical and mutation analysis demonstrate that procollagen VII is processed to collagen VII through removal of the NC-2 domain. J. Cell Biol. 131:551-559.

30. Wessel, D., and U. Flügge. 1984. A method for the quantitative recovery of proteins in dilute solution in the presence of detergents and lipids. Anal. Biochem. 138:141-143.

31. Nara, K., K. Nakanishi, H. Hagiwara, K.-I. Wakita, S. Kojima, and S.
Hirose. 1989. Retinol-induced morphological changes of cultured bovine endothelial cells are accompanied by a marked increase in transglutaminase. J. Biol. Chem. 264:19308-19312.

32. Gibran, N.S., D.M. Heimbach, and K. Holbrook. 1995. Immunolocalization of FXIIII a + dendritic cells in human burn wounds. J. Surg. Res. 59:378386.

33. Lapiere, J.C., J.D. Chen, T. Iwasaki, L. Hu, J. Uitto, and D.T. Woodley. 1994. Type VII collagen specifically binds fibronectin via a unique subdomain within the collagenous triple helix. J. Invest. Dermatol. 103:637-641.

34. Barsigian, C., A.M. Stern, and J. Martinez. 1991. Tissue (type II) transglutaminase covalently incorporates itself, fibrinogen, or fibronectin into high molecular weight complexes on the extracellular surface of isolated hepatocytes. J. Biol. Chem. 266:22501-22509.

35. Fesus, L., M.L. Metsis, L. Muszbek, and V.E. Koteliansky. 1986. Transglutaminase-sensitive glutamine residues of human plasma fibronectin revealed by studying its proteolytic fragments. Eur. J. Biochem. 154:371-374.

36. Tyrell, D.J., W.S. Sale, and C.W. Slife. 1988. Fibronectin is a component of the sodium dodecyl sulfate-insoluble transglutaminase substrate. J. Biol. Chem. 263:8468-8469.

37. LeMosy, E.K., H.P. Erickson, W.F. Beyer, J.T. Radek, J.M. Jeong, S.N.P. Murthy, and L. Lorand. 1992. Visualization of purified fibronectin-transglutaminase complexes. J. Biol. Chem. 267:7880-7885.

38. Gentile, V., V. Thomazy, M. Piacentini, L. Fesus, and P.J.A. Davies 1992. Expression of tissue transglutaminase in Balb-c 3 T3 fibroblasts: effects on cellular morphology and adhesion. J. Cell Biol. 119:463-474.

39. Piacentini, M., M.P. Ceru, L. Dini, M. Dirao, L. Piredda, V. Thomazy, P.J.A. Davies, and L. Fesus. 1992. In vivo and in vitro induction of tissue transglutaminase in rat hepatocytes by retinoic acid. Biochim. Biophys. Acta. 1135: 171-179.

40. Poon, M.-C., J.A. Russell, S. Low, G.D. Sinclair, A.R. Jones, W. Blahey, B.A. Ruether, and D.I. Hoar. 1989. Hemopoietic origin of Factor XIII a-subunits in platelets, monocytes and plasma. Evidence from bone marrow transplantation studies. J. Clin. Invest. 84:787-792.

41. Shainoff, J.R., D.A. Urbanic, and P.M. Di Bello. 1991. Immunoelectrophoretic characterization of the cross-linking of fibrinogen and fibrin by factor XIIIa and tissue transglutaminase. J. Biol. Chem. 266:6429-6437.

42. Candi, E., G. Mlelino, G. Mei, E. Tarcsa, S.-I. Chung L.N. Marekov, and P.M. Steinert. 1996. Biochemical, structural and transglutaminase substrate properties of human loricrin, the major epidermal cornified cell envelope protein. J. Biol. Chem. 270:26382-26390.

43. Dolynchuk, K.N., R. Bendor-Samuel, and J.M. Bowness. 1994. Effect of putrescine on tissue transglutaminase activity in wounds: decreased breaking strength and increased matrix fucoprotein solubility. Plast. Reconstr. Surg. 93:567-573.

44. Wang, J.Y., and L.R. Johnson. 1992. Role of transglutaminase and protein cross-linking in the repair of mucosal stress erosions. Am. J. Physiol. 262 G818-G825.

45. Eitan, S., A. Solomon, V. Lavie, E. Yoles, D.L. Hirschberg, M. Belkin, and M. Schwartz. 1994. Recovery of visual response of injured adult rat optic nerves treated with transglutaminase. Science (Wash. DC). 264:1764-1768. 